\title{
Artelogie
}

Recherche sur les arts, le patrimoine et la littérature de l'Amérique latine

$4 \mid 2013$

Fêtes et célébrations en Amérique latine

\section{A Província em festa : celebrações e poderes simbólicos na visita de sua Majestade Imperial à Parahyba do Norte - 1859}

Carla Mary S. Oliveira e Cláudia Engler Cury

\section{(2) OpenEdition}

\section{Journals}

\section{Edição electrónica}

URL: https://journals.openedition.org/artelogie/5958

DOI: 10.4000/artelogie.5958

ISSN: 2115-6395

Editora

Association ESCAL

Refêrencia eletrónica

Carla Mary S. Oliveira e Cláudia Engler Cury, «A Província em festa : celebrações e poderes simbólicos na visita de sua Majestade Imperial à Parahyba do Norte - 1859», Artelogie [Online], 4 | 2013, posto online no dia 02 fevereiro 2013, consultado o 01 dezembro 2021. URL: http://journals.openedition.org/ artelogie/5958 ; DOI: https://doi.org/10.4000/artelogie.5958

Este documento foi criado de forma automática no dia 1 dezembro 2021.

Association ESCAL 


\title{
A Província em festa : celebrações e poderes simbólicos na visita de sua Majestade Imperial à Parahyba do Norte - 1859
}

\author{
Carla Mary S. Oliveira e Cláudia Engler Cury
}

\section{Introdução}

1 Em 13 de abril de 1860 o então presidente da província da Parahyba do Norte, Ambrósio Leitão da Cunha, apresentava o Relatório a seu sucessor nomeado pela Corte, Luiz Antonio da Silva Nunes, cumprindo a regulamentação então vigente no que se refere à transmissão do cargo que ocupava. Fato corriqueiro da administração imperial, tal ato se diferencia significativamente em relação àqueles do mesmo tipo que o antecederam e também aos que o seguiram : se inicia justamente pela descrição sucinta da Visita Imperial de Sua Majestade D. Pedro II, acompanhado de sua Augusta Consorte, D. Teresa Cristina, e de uma comitiva numerosa, aos quais os paraibanos, principalmente os habitantes da capital da província ${ }^{1}$, receberam em exultante clima de festas e celebrações, pelo curto período compreendido entre 24 e 30 de dezembro de 1859 :

o lugar que me coube, como presidente da província, na festa imensa, com que aqui forão recebidos SS. MM. II., pura significação do patriotismo dos Parahybanos, e do profundo amor e veneração que tributamos ao Augusto Chefe da Nação e á Familia Imperial, proporcionou-me os meios de presenciar de perto, e por consequência de poder relatar minuciosamente á $\mathrm{V}$. Exc. todos os successos festivos d'aquelles seis dias notaveis, em que vi trocadas as fadigas e dissabores da administração por momentos de indisivel prazer, cuja grata recordação conservarei sempre; mas o fervoroso acolhimento, que aqui tiverão SS. MM. II., as provas de amor e veneração ás Suas Augustas Pessoas, que á cada passo, e como á porfia, procuravão manifestar, pelo modo mais desinteressado, todas as classes de cidadãos sem distincção alguma, a angelica bondade, com que taes demonstrações forão sempre recebidas pelo Regio Par, entregue por toda a parte, com ilimitada confiança, as ruidosas manifestações 
de prazer de seus subditos, podem ser objecto de sentimento, como forão, mas nunca o serão de narração fiel, como V. Exc. sabe ; por isso abstendo-me de entrar em promenores á esse respeito, occuparei a attenção de V. Exc. Com a singela e succinta exposição dos factos relativos á visita Imperial, por me parecer que devem ficar consignados em documentos da natureza deste, tanto mais quanto tem V. Exc. de dar noticia desses factos officialmente ao Governo Imperial em virtude de determinação contida em aviso expedido pela Secretaria d'Estado dos Negocios do Imperio, que eu tratava de cumprir (CUNHA, 1860 : 01-02).

2 Os jornais paraibanos do ano de 1859, o Relatório do presidente da província referido acima e as cadernetas de viagem de D. Pedro II nos serviram como referência principal na tessitura deste artigo. Optamos por privilegiar os textos publicados ou redigidos à época com o intuito de produzir uma escrita historiográfica que nos permitisse uma aproximação com o clima de festa e celebrações empreendidos por homens e mulheres da província na recepção aos imperadores do Brasil e, quem sabe, fragá-los em suas emoções por algum descuido deixado pelos textos escritos, já que da visita dos consortes não temos nenhuma imagem.

3 No caso da historiografia paraibana tomamos como referência, além dos jornais já mencionados anteriormente, uma pequena brochura intitulada Presença de D. Pedro II na Paraíba (ALMEIDA, 1982) ${ }^{2}$ por ser uma das raras produções locais que pretenderam registrar a passagem do monarca pela Parahyba do Norte. Almeida transcreve trechos das cadernetas de viagem de Pedro II e faz suas próprias considerações acerca do episódio da visita, possibilitando que o leitor apreenda as representações do autor acerca da presença de Suas Majestades Imperiais na capital da província e em algumas localidades do interior. $\mathrm{O}$ médico-historiador ressalta, por exemplo, que todas as despesas da viagem

correram por conta pessoal de D. Pedro II, como se o imperador estivesse empreendendo uma excursão turística para regalo íntimo ; como se não estivesse no desempenho de missão inerente às suas funções conspícuas (ALMEIDA, 1982: 54).

Vale ainda ressaltar que a escrita produzida pelo autor pretende dar ao leitor a impressão de alguém que testemunhou os acontecimentos e os está narrando in locu.

A cidade da Parahyba no final da década de 1850 não era grande coisa e se assemelhava, neste aspecto, a todas as outras pequenas capitais de províncias periféricas do vasto Império brasileiro : a urbe se constituía como pouco mais que um conjunto de arruados de terra, apinhada de casas rústicas e alguns poucos casarões senhoriais, além de conventos e igrejas barrocas, onde as irmandades e congregações religiosas ditavam o ritmo da vida cotidiana dos habitantes com o calendário litúrgico e os festejos religiosos e profanos correspondentes.

6 O norte-americano Daniel Parish Kidder, por exemplo, em suas viagens como missionário metodista pelas províncias do norte do Brasil, entre 1840 e 1842, passou pela Parahyba durante alguns dias, justamente no período dos festejos dedicados à padroeira da cidade, Nossa Senhora das Neves, na primeira semana de agosto. Com certo espanto, o pastor registra o sincretismo entre os serviços religiosos da novena $\mathrm{e}$ rezas realizadas na Igreja Matriz e a festa profana, onde o espocar de fogos e rojões e outros comportamentos condenáveis para o puritano juntavam "familias inteiras, incluindo mães e suas filhas", que assistiam, já tarde da noite, ao "mais baixo e vulgar tipo de espetáculo burlesco", de "tendências imorais - e tudo sob o nome da religião!" (KIDDER, $1845: 185-186)$. 
7 A cidade muito pouco mudou depois da visita de Kidder, que a descreveu de forma bem lacônica :

As ruas são largas, pavimentadas com uma espécie de xisto argiloso. As pedras, muito desgastadas. Algumas gelosias ${ }^{3}$ velhas, apoiadas em cornijas de pedra esculpida, são vistas na Paraíba, e o aspecto geral da cidade é bastante antigo (KIDDER, 1845 : 187).

8 Cerca de 16 anos depois da visita do missionário, a Parahyba ainda enfrentava sérios problemas de infraestrutura : suas ruas eram esburacadas, a maioria de areia ou barro, quase sempre não permitindo o tráfego de carroças e muito menos de carruagens ou coches, principalmente durante o período chuvoso do inverno ; não havia sistema de esgotos; a qualidade dos alimentos, especialmente da carne vendida na cidade, era péssima; o porto que a servia estava mal aparelhado e não existia ligação terrestre decente - por estrada ou ferrovia - nem com as províncias vizinhas, notadamente Pernambuco, cujo porto era na verdade o grande responsável pelo escoamento da produção paraibana, e tampouco com as maiores povoações do interior da própria província. Essa situação aparece claramente nos relatórios apresentados pelos presidentes da Parahyba que exerceram o cargo nos períodos imediatamente anteriores à visita imperial.

9 Henrique de Beaurepaire Rohan, por exemplo, em seu Relatório datado de 20 de setembro de 1858 , ao tratar das ruas da capital, asseverava :

Os arruamentos n'esta cidade nunca forão, nem ainda estão sujeitos a plano algum, quer em relação aos alinhamentos, quer em relação ao nivelamento. Cada um edifica á sua guisa, e d'ahi resulta esse labyrinto, em que se vai sensivelmente convertendo a cidade. [...] Em verdade, o transito entre o Varadouro, e o alto da cidade é penoso, por causa de suas ladeiras ingremes. [...] Tencionava mandar regularisar, para ser convenientemente calçada, a ladeira do Varadouro ; mas esta obra tornava-se nimiamente dispendiosa ; e tenho para mim que, construído o cáes, será mais conveniente que a communicação do desembarque com a cidade se faça por meio de uma rua, que não tenha uma subida tão ingreme como aquella (ROHAN, $1858: 21-23)$.

\section{Os rituais da monarquia brasileira e as viagens do Imperador}

10 O Império brasileiro já surgiu intrinsecamente amalgamado ao campo do simbólico. Ainda antes da Independência, quando o país foi alçado à condição de Reino Unido junto a Portugal e Algarves, a família real lusa teve o cuidado de trasladar minuciosamente às paragens tropicais, com D. João à frente, os rituais cotidianos da corte lisboeta, tanto em seus festejos e datas comemorativas da coroa, como também em seus ritos de sagração e exposição pública do poder político. Para Lília Schwarcz, nesse sentido, após garantir a autonomia política e sua própria manutenção nas rédeas da nova nação, a realeza brasileira soube atualizar a tradição europeia "e a fez dialogar com as representações locais, anteriores a seu estabelecimento" (SCHWARCZ, 2001b : 08).

11 Assim, não é de causar espécie que o monarca do Império Brasileiro tenha adotado diversos elementos distintivos dos trópicos na ritualística cotidiana a que estava submetido. Esse fato justifica "o manto verde como a nação, a coroa e a murça de penas de papo de tucano" (SCHWARCZ, 1998: 16-17), bem como o hábito de visitar seus domínios, resgatando o espírito das entradas reais praticadas em Portugal desde o medievo. É esse 
rito em especial, aliás, com seus sentidos simbólicos muitas vezes nem tão claramente perceptíveis, que nos interessa aqui discutir.

As festas eram necessárias, sobretudo, como "instrumentos estratégicos na afirmação quase diária da realeza” (SCHWARCZ, 1998: 253). Na Corte, o Imperador, sua consorte e herdeiros estavam submetidos a um calendário festivo que ia de janeiro a dezembro, sem interrupções. Celebravam-se aniversários de nascimentos e falecimentos, datas cívicas, bodas, datas relativas à morte, nascimento ou canonização dos santos padroeiros, sagração, além de qualquer outra data que passasse a marcar de alguma forma o cotidiano da família imperial (SCHWARCZ, 2001a : 610). Cada festividade destas tinha seu protocolo específico, que demandava uma preparação esmerada e gastos que, hoje, podem mesmo parecer absurdos.

Do mesmo modo, nas viagens do monarca pelo território de seu Império, pressupunhase reproduzir, ao menos minimamente, o cerimonial das efemérides da Corte, onde uma grande coreografia era montada e, junto com a família imperial, era a própria corte que ganhava, aos poucos, as ruas e desenhava (...) uma conformação política dificilmente percebida de outra maneira por essa sociedade majoritariamente analfabeta e que entendia melhor o espetáculo visual do que o texto escrito (SCHWARCZ, 2001b : 34).

14 Atos praticados nestas recepções festivas, como entrega das chaves da cidade, discursos, homenagens, beija-mãos, concessão de títulos e mercês, portanto, se imbuíam de um sentido muito mais forte quando se davam no seio de uma visita imperial. Havia que se preparar tudo nos mínimos detalhes, a fim de que a agenda apertada de Suas Majestades Imperiais fosse cumprida à risca. Na Parahyba de 1859, foi com extrema diligência que o presidente da província, os deputados da Assembleia e a Câmara Municipal da capital se empenharam para atender às expectativas não só do ilustre visitante e de sua comitiva, mas também da população local, que pela primeira vez teria a oportunidade de presenciar o séquito imperial diante de seus próprios olhos, de sentir-se de fato como parte do vasto Império brasileiro.

\section{Os preparativos da Parahyba do Norte para a chegada do Séquito Imperial}

15 A cidade da Parahyba, portanto, teria que sofrer grandes mudanças para se colocar minimamente em condições de receber o monarca brasileiro em sua visita ao norte do país, da qual o governo provincial foi notificado, por meio de Aviso Imperial, em 5 de setembro de 1859, apenas com cerca de três meses e meio de antecedência à chegada do soberano para sua visita (PINTO, 1977:274).Para dar conta dos gastos então considerados imprescindíveis à correta preparação da capital e do Palácio do Governo para a recepção às Suas Majestades Imperiais, a Assembleia Provincial disponibilizou, por meio da Lei $\mathrm{n}^{\circ} 30$, datada de 3 de outubro de 1859, um crédito ilimitado ao gabinete da presidência da Parahyba para as despesas que se fizessem necessárias (CUNHA, 1860 : 04). Numa terra pobre e necessitada de tantas coisas, assistiu-se a uma verdadeira farra com a verba pública : compraram-se móveis novos, no Recife, para uso das visitas no Paço; reformou-se o telhado do prédio para dar fim às constantes goteiras que poderiam importunar a comitiva imperial ; comprou-se tecidos finos para as cortinas; renovou-se a louça; abasteceu-se a despensa com iguarias compradas em Pernambuco. 
Era preciso estar à altura de acontecimento tão auspicioso e singular para os parahybanos...

Em seu mesmo Relatório datado de 14 de abril de 1860, o presidente Leitão da Cunha, por sua vez, registrava parte destas despesas :

Para a recepção de SS. MM. II. resolvi mandar fazer serios reparos no palacio da presidencia e na Igreja do collegio, que lhe serve de capella, afim de pôr o antigo hospicio dos Jesuitas em estado condigno ao alto fim, a que se ia destinar.// Dei conta minuciosa das obras feitas ao Governo Imperial, de quem aguardava a approvação da despesa feita.// O palacio acha-se além disso completamente mobilhado sem nada faltar-lhe, de forma que está hoje uma habilitação condigna da posição do delegado do Governo Imperial. Creio mesmo, que nenhuma outra lhe é superior a esse respeito.// A capella tambem tem todos os paramentos e serviço dos altares necessario. Da prata, que antigamente era propriedade da Igreja, e que se achava em deposito na thesouraria da fasenda, mandei fornecer á capella os objectos constantes do inventario da mobilia de palacio, que será apresentado a V. Exc. (CUNHA, $1860: 30$ ).

17 Já em outra correspondência expedida por Leitão da Cunha ao juiz da comarca de Pilar em $1^{\circ}$ de outubro de 1859 , há toda uma orientação acerca dos procedimentos que deveriam ser tomados a fim de preparar a vila e povoados próximos para a recepção ao monarca :

Tendo Sua Magestade O Imperador de visitar esta Provincia, onde Podera Achar-se por todo o mez de Novembro próximo futuro, provavelmente Quererá percorrer os principaes povoados do interior maes proximos a costa ; e nesse cazo Terá de passar por essa Villa do Pilar, e pousar na povoação de Gurinhem da comarca de sua jurisdição.// Cumpre pois que V. Sa., como primeira autoridade nesses lugares, promova os necessários arranjos para a conveniente recepção de Sua Magestade.// Confio que V. Sa. E os habitantes da sua comarca se prestarão com gosto e boa vontade a honrar a Sua Magestade na Visita que ahi tem de Fazer, e que aproveitar-se-hão de tão boa oportunidade para manifestarem ao mesmo Augusto Senhor o amor respeito, e dedicação que todos nós Lhe tributamos (ALMEIDA, $1982: 55)$.

O fato é que mesmo o monarca viajando às suas próprias expensas (ALMEIDA, 1982 : 93), não havia verba suficientemente disponível no Tesouro da Parahyba para custear condignamente os preparativos para a visita de D. Pedro II. Tanto era assim que já em agosto, antes mesmo do Aviso Imperial datado de 5 de setembro de 1859 que dava conta da planejada viagem imperial às províncias do Norte, o Ministro dos Negócios do Império comunicou a Leitão da Cunha oficiosamente a programação - daí talvez o presidente referir-se ao mês de novembro para a chegada do Imperador em sua carta ao juiz de Pilar - e tal informação chegou acompanhada da quantia de $1: 000 \$ 000^{4}$ de réis, "destinada à cobertura das despesas necessárias ao preparo dos aposentos em que o Imperador e a Imperatriz deveriam hospedar-se". Cerca de um mês depois, junto com o Aviso Imperial, chegaram mais 3:000\$000 de réis destinados à aquisição de mobília e itens de decoração (ALMEIDA, $1982:$ 57).

Na Fala do Trono com que D. Pedro II encerrou a $3^{\text {a }}$ Sessão da $10^{\text {a }}$ legislatura da Assembleia Geral na Corte, em 11 de setembro de 1859, é divulgada publicamente a intenção de viajar às províncias do Norte, e o monarca a justificativa da seguinte maneira :

Para melhor conhecer as provincias do meu Imperio, cujos melhoramentos moraes e materiaes são o alvo de meus constantes desejos, e dos esforços do meu governo, decidi visitar as que ficão ao norte da do Rio de Janeiro, sentindo que a estreiteza do 
tempo que medea entre as sessões legislativas me obriguem a percorrer sómente as provincias do Espirito-Santo, Bahia, Sergipe, Alagoas, Pernambuco e Parahyba, reservando a visita das outras para mais tarde (P. de S., 1861/1862 : IX). os preparativos da visita imperial mostrou-se logo totalmente insuficiente para as obras e aquisições necessárias à recepção dos monarcas na província. Maurílio de Almeida destaca, a partir de documentação hoje já extraviada do Arquivo Público da Paraíba, que Leitão da Cunha chegou a trocar vasta correspondência com o Conselheiro Ângelo Muniz da Silva Ferraz, na Corte, dando conta do conjunto de obras e aquisições necessárias no Palácio do Governo e descriminando o total de gastos que já havia feito na tentativa de adaptar minimamente aquele prédio para a hospedagem dos monarcas :

Havendo-me V. Exa. Determinado que fizesse decorar o Palácio da Presidência, onde devem residir SS.MM.II. enquanto aqui estiverem, vi logo que não existe no Palácio cousa alguma que pudesse ser aproveitado convenientemente para o serviço de SS.MM., no estado em que se achava. A mobília toda da casa e o serviço de mesa eram tão ordinários ou deficientes que forçosamente deviam ser substituídos ou aumentados. Além disso, as salas e quartos ou não tinham papel nas paredes e esteiras no chão, ou as tinham completamente estragados. Nestes termos, resolvi o caso de modo conveniente a receber Sua Magestade não com luxo, mas ao menos com a necessária decência, o que não pude conseguir apesar da mais restrita economia que empreguei para haver a mobília e objetos de decoração, sem que as respectivas contas se elevassem a $6: 797 \$ 920$ (...) (ALMEIDA, $1982: 58$ ).

Ora, mesmo sem ter conseguido fazer as reformas e trocar o mobiliário, decoração e serviços de louça do Palácio do modo que considerava ser o correto e desejável, o presidente da Parahyba do Norte extrapolava a verba fornecida pelo governo da Corte em quase $2: 800 \$ 000$ de réis... Daí, portanto, a Lei da Assembleia Provincial datada de outubro, abrindo os cofres públicos para que se completassem os preparativos. E aqui não estamos falando ainda da limpeza das ruas, pintura das casas das vias por onde circularia o monarca e seu séquito e tampouco dos arcos triunfais efêmeros, guirlandas, vestimentas e outros paramentos necessários à procissão do desembarque no Varadouro até a Igreja Matriz, para a realização do Te Deum ${ }^{5}$, nem mesmo dos deslocamentos do imperador pelas paragens próximas à capital, mas por enquanto, apenas da reforma e adaptação do Palácio que hospedaria Suas Majestades Imperiais.

\section{A visita de Pedro II à Parahyba na perspectiva dos periódicos provinciais}

Numa província em que a ligação entre suas cidades e vilas era precária e de uso penoso, não surpreende que os periódicos circulantes na época da visita de D. Pedro à Parahyba do Norte se esmerassem por descrever, nos mínimos detalhes e pormenores, todo o cerimonial e as celebrações e homenagens que tiveram ocasião não somente na capital, mas também nas localidades do interior visitadas pelo monarca, afinal, seria praticamente impossível a um grande contingente da população residente no interior deslocar-se à capital ou às vilas visitadas a fim de presenciar pessoalmente tais efemérides, não só pela questão das dificuldades de deslocamento, mas também pela falta de hospedagem na capital.

Infelizmente, a maior parte dos periódicos publicados na Parahyba do Norte ao longo do XIX não teve suas coleções preservadas condignamente nos arquivos locais, públicos 
ou particulares, e tampouco no acervo da Biblioteca Nacional do Rio de Janeiro. Quase sempre encontra-se nestes locais de pesquisa, notadamente na hemeroteca do Instituto Histórico e Geográfico Paraibano, em João Pessoa, apenas exemplares esparsos e de períodos não coincidentes com a visita de Suas Majestades Imperiais à província. No entanto, hoje temos acesso a parte das notícias publicadas à época, graças à diligência de Irineu Ferreira Pinto, historiador diletante e membro do Instituto Histórico e Geográfico Paraibano em começos do século XX, que transcreveu no segundo volume de seu Datas e notas para a História da Paraíba longos trechos d'O Despertador (PINTO, 1977 : 274-280), jornal que dedicou diversas páginas à descrição minuciosa das festividades e celebrações dedicadas à visita imperial, bem como o relato do itinerário percorrido pelos monarcas e seu séquito assim que desembarcaram em solo parahybano, na tarde de 24 de dezembro de 1859, bem como de todas as celebrações realizadas e atos praticados pela comitiva nos poucos dias em que permaneceram na província.

\title{
'O Despertador' e os rituais festivos por ocasião da visita da comitiva imperial
}

24 Fica evidente, nas descrições laudatórias publicadas n'o Despertador, que existia realmente um clima de euforia pública entre os parahybanos no momento da chegada da comitiva imperial e seu desembarque no cais do Varadouro :

\begin{abstract}
Uma linha, formada por muitas canôas, jangadas, barcassas e hyates, todos embandeirados, existia em frente da povoação, cuja praia estava apinhada de povo. Dentro d'agoa, e em alguma distancia de terra havia uma especie de forte, cheio de meninas e de muitas pessoas, e quando o «Apa » ia passando, vivas enthusiasticos acompanhados de muito fogo do ar, sahirão dessa extensa linha de barcos de nossa pequena cabotagem, desse forte, e de toda população que se aglomerava na praia para ver passar o vapor, que condusia os Sagrados Penhores da felicidade e prosperidade dos Brazileiros !// Por esse tempo o caes e praça do Varadouro ja estava apinhado de povo ; o pavilhão continha muitas senhoras, e todos esperavam com anciedade o aparecimento do "Apa ».// As tres horas e um quarto da tarde aquelle vapor dêo volta ao boqueirão, e avistou a cidade e então de todos os angulos della subião ao ar um sem numero de girandolas, repicando ao mesmo tempo todos os sinos. // Logo que o "Apa » fundiou, foi á bordo o S. Exc. O Sr. presidente da provincia, acompanhado do seu ajudante d'ordens, o qual voltou pouco depois trasendo a certesa de que Sua Magestade o Imperador desembarcaria as $4 \mathrm{e} \frac{1}{2} \mathrm{~h}$ horas, devendo o Te-Deum ter lugar na mesma occasião. // De momento a momento o povo ia afluindo cada vez mais - A camara municipal, com seu uniforme proprio, ali se achava ; o Sr. visitador, acompanhado do Sr. vigario desta capital e de todo clero, também já tinhão comparecido, os Srs. 4 juizes de paz desta cidade, encarregados da direcção do prestito, estavão presentes : nada pois faltava para a recepção de Suas Magestades (PINTO, 1977 : 274-275).
\end{abstract}

25 A capital da província, portanto, exultava em regojiso pela presença de Comitiva tão Augusta em suas terras. É interessante notar que a receptividade do povo parece ter sido a tônica em todas as províncias visitadas por D. Pedro II entre fins de $1859 \mathrm{e}$ começos de 1860. No "Proêmio" das Memórias da viagem de SS. Magestades Imperiais às províncias da Bahia, Pernambuco, Parahiba, Alagoas, Sergipe, e Espirito Santo, publicação coligida e organizada por alguém que se assinava apenas como "P. de S." e inicialmente prevista para 6 tomos mas da qual só foram lançados os 2 primeiros, referentes às províncias de Bahia e Pernambuco, lê-se uma descrição genérica destes momentos de recepção do monarca e de sua comitiva na chegada às capitais provinciais : 
Emprehendendo o trabalho que hoje apresentamos ao publico, não tivemos por unico objecto satisfazer a curiosidade do leitor com a descripção das festas, a que deo motivo em diversas provincias a visita imperial.// Que estas festas serião tão pomposas e brilhantes quanto o permittissem as circunstancias de cada lugar, era cousa já prevista e esperada : mas no meio de todas as pompas externas, no meio de todas as demonstrações de alegria que passão com a occasião, o observador attento compraz-se de notar um fato digno de ser transmittido ao conhecimento da posteridade como caracteristico do actual reinado. Queremos fallar da unanimidade, com que se pronunciárão os sentimentos das diversas classes a respeito de tudo quanto podia provar que assim nas capitaes, como nos ultimos lugarejos das provincias, foi o Senhor D. Pedro II recebido e considerado como um Brasileiro a quem os seus compatriotas conferirião o lugar de primeiro representante da nação, se já lhe não competisse por direito ; como um pai entre filhos amantes e respeitosos; como o mais querido dos irmãos no seio de uma grande familia.// Simplicidade no tratamento, delicadeza nas maneiras, constante disposição para dispensar a pompa e apparato que de ordinario rodeão a realeza, solicita applicação aos assumptos de interesse geral com preterição dos commodos pessoaes, e de tudo quanto podesse dar á sua visita o caracter de uma viagem de recreio, summa benignidade para attender as queixas, ainda mais humilde dos seus subditos, desejo sincero de honrar e distinguir o verdadeiro merito, amor da justiça, generosidade e philantropia levadas a ponto que não póde ser excedido, foi o que o Imperador apresentou aos olhos de todos desde o primeiro até o ultimo momento de sua estada nas províncias (P. de S., 1861/1862 : V-VI).

\section{Recepção e visão dos parahybanos acerca da visita do Imperador}

$\mathrm{Na}$ longa narrativa presente n'O Despertador e transcrita por Irineu Pinto quase que se tem acesso a uma descrição densa, no melhor sentido antropológico. $O$ trajeto entre o desembarque do vapor Apa no pavilhão montado no cais do Varadouro e a Igreja Matriz, onde seria celebrado o Te Deum, e daí ao Palácio do Governo Provincial, que passou a ser denominado de Paço a partir de então e em todas as descrições da visita imperial, foi detalhadamente descrito no jornal, e a todo momento se ia destacando a alegria contagiante dos populares :

Não é possível descrever-se o enthusiamo que em todo esse trajecto mostrou o povo Parahybano. De todas as varandas, de todas as casas os homens, as senhoras davão vivas aos Augustos visitantes, as senhoras deitavão-lhes flores em sua passagem; o povo que os acompanhava correspondia e repetia estes vivas, e S.S. M.M. sempre os agradecia com a maior afabilidade, mostrando constantemente a maior satisfação, por se acharem no meio de um povo que tanto os victoriava, e que assim mostrava que os amava, que os adorava mesmo. Na rua do Paço atravessou o prestito por baixo de um arco, que ali fôra feito a expensas das pessoas do commercio, e que em verdade estava bem decorado.// No fim da rua d'Areia existia outro arco, contendo disticos analogos, e cuja vista era encantadora : era guarnecido por vinte meninas vestidas de branco, cabellos soltos, com capella de flores brancas, trazendo faxas de rica e larga fita de gorgurão de seda, com amarello nas extremidades e verde no centro onde se lião em letras de ouro os nomes de cada uma das provincias do imperio (PINTO, 1977 : 275-276).

Na figura a seguir, que traz uma planta da Cidade da Parahyba datada de 1858, é possível perceber o caminho percorrido pela procissão em honra de D. Pedro e da Imperatriz, logo após sua chegada e depois do Te deum na Igreja Matriz. 
Fig. 01 - Detalhe da Planta da Cidade da Parahyba, s.d.

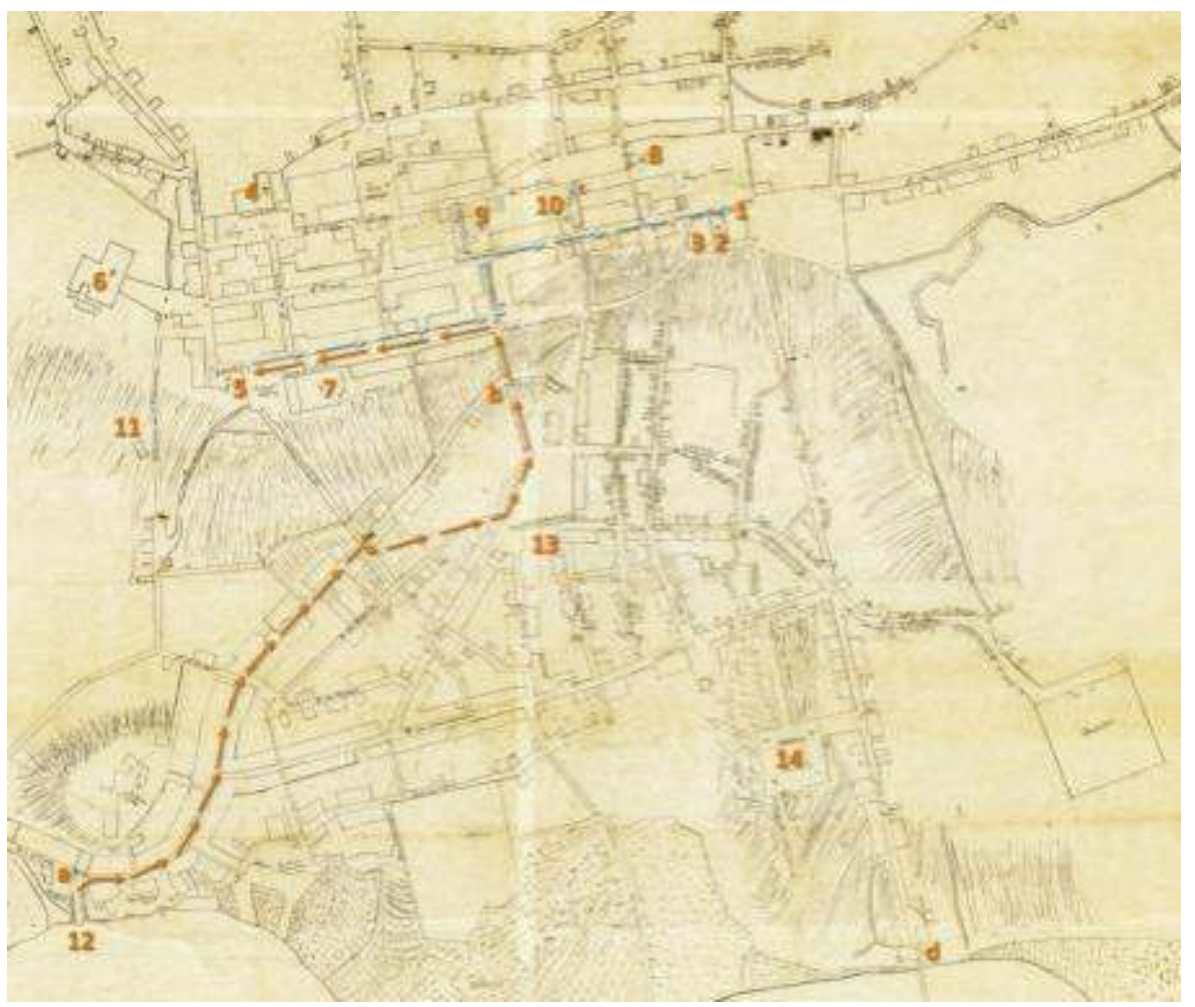

Provavelmente se trata da planta encomendada pelo presidente Beaurepaire Rohan ao engenheiro militar Alfredo de Barros Vasconcellos em 1858, pois nela não constam algumas ruas abertas a seu mando, no segundo semestre daquele ano

LEGENDA : 1) Palácio do Governo ; 2) Igreja do Colégio ; 3) Lyceu Provincial ; 4) Igreja e Convento do Carmo ; 5) Igreja Matriz ; 6) Convento e Igreja de São Francisco ; 7) Igreja e Mosteiro de São Bento ; 8 ) Igreja de N. Sra. das Mercês ; 9) Igreja e Santa Casa da Misericórdia ; 10) Igreja de N. Sra. do Rosário ; 11) Casa da Pólvora ; 12) Cais do Varadouro ; 13) Quartel de $1^{a}$ linha ; 14) Cadeia ; "a", "b", "c" e "d") arcos triunfais erguidos para a recepção de Suas Majestades Imperiais ; trajeto de "12" a " 5 " : do desembarque ao Te Deum, na Ig. Matriz ; trajeto de "5" a "1", passando por " $\mathrm{C}$ " : do Te Deum ao Palácio. Setor de Cartografia, Biblioteca Nacional do Rio de Janeiro (ARC.017,07,021 on)

Arcos triunfais de arquitetura efêmera, buquês e guirlandas de flores eram homenagens costumeiras neste tipo de cerimônia pública no Império. No entanto, pode causar certo estranhamento a um leitor do século XXI que se compusesse uma profusão de versos para serem declamados por meninas e meninos aos ilustres visitantes: "Deos te salve ó Soberano,/Filho de Pedro Primeiro,/ Deos te salve, Augusta Esposa,/Do Monarcha Brazileiro!" (PINTO, 1977 : 276). Mesmo declamados, tais dísticos também enfeitavam os arcos triunfais construídos especialmente para a recepção dos monarcas, reforçando ainda mais a louvação de seus poderes simbólicos e a condição de súditos leais daqueles parahybanos que os recebiam...Distinção às suas Majestades Imperiais.

Os hinos também se inscrevem no universo das celebrações e podem garantir que determinados episódios ou pessoas sejam imortalizados e façam parte de futuras comemorações que deveriam refrescar as memórias acerca de acontecimentos passados. Nesse sentido, a passagem dos augustos imperadores pela província parahybana não deixou de propiciar a elaboração de um hino em sua homenagem.

o hino composto por Tertuliano de Medeiros foi entoado em mais de uma ocasião, o que denota ensaios prévios para sua execução. Maurílio de Almeida destaca o tom singelo dos versos, transcritos em sua brochura : 
De dezembro o vinte e quatro Raiou alegre, e fagueiro./Já se acha em nossos braços/O Monarca Brasileiro./ (...)/ Temos por dita/ Um céu d"anil/ Monarca exímio/ De encantos mil./ Nossa Excelsa Imperatriz/ maior das Soberanas,/ Honrou com sua visita/ As plagas paraibanas./ (...) / Entre as Nações do Universo,/ É o Brasil mui ditoso,/ Áureo cetro nele empunha/Um Monarca estudioso./ (...) / Paraibanos cantemos/ Neste tão festivo dia,/A Pedro e a tirse bela,/Hinos d'amor, d'alegria./ (...) / Seja o céu sempre propício/ A Pedro, a sua consorte,/ Que feliz se tornará/ O Brasil de Sul a Norte./ (...) / Aos Augustos Visitantes/ Juremos sempre amizade,/ Juremos ser sempre unidos,/ Juremos fidelidade (ALMEIDA, 1982 : 86-87).

Enquanto D. Pedro viajou às Vilas de Pilar e Mamanguape, em 26 e 27 de dezembro, a Imperatriz Thereza Christina cumpriu um protocolo comum à época junto à Irmandade da Venerável Ordem Terceira de Nossa Senhora do Carmo da capital parahybana : foi empossada como Priora Perpétua e Protetora daquela agremiação religiosa, cargo honorífico para o qual havia sido nomeada doze anos antes. Mais uma vez, é Irineu Pinto quem nos permite conhecer o teor do documento de registro desta homenagem :

Aos vinte e sete dias do mez de Dezembro do anno do Nascimento de Nosso Senhor Jesus Christo de mil oitocentos e cincoenta e nove, nesta cidade da Parahyba do Norte, na capella da veneravel Ordem Terceira de Nossa Senhora do Carmo, teve a mesma ordem a distincta honra de receber a visita da Muito Alta e Muito Poderosa Senhora Dona Thereza Christina Maria, Nossa Excelsa Imperatriz, Augusta Consorte do Muito Alto e Muito Poderoso Senhor Dom Pedro de Alcantara Bourbon, Segundo Imperador deste vasto e aurifero Imperio do Brazil, em visita as provincias do Norte, achando-se reunidos os Irmãos Terceiros abaixo assignados. E sendo a mesma Augusta Senhora Priora perpetua e Protectora desta Veneravel Ordem, como nos constou por Aviso da Secretaria de Estado dos Negocios do Imperio, de vinte e seis de Setembro de mil oitocentos quarenta sete, cargo este com que se Dignou de Honrar a mesma Veneravel Ordem, delle se dá por seu consentimento por empossada. E não só para que isto conste a todo o tempo, como para memorar tão honrosa visita, permittio a mesma Augusta Senhora que se lavrasse o presente termo, em que dignou de assignar com a sua comitiva o Excellentissimo Senhor Veador Conselheiro Luiz Pedreira do Couto Ferraz, Guarda Roupa Conselheiro Antonio Manuel de Mello, Secretario Geral interino do Ministerio do Imperio Dionisio da Cunha Ribeiro Feijó, Capellão de S.S.M.M.I.I. o Conego Antonio José de Mello, Vice-Almirante Joaquim Marques Lisboa, Chefe de Divisão Francisco Manuel Barroso da Silva, Capitão de Mar e Guerra Francisco Pereira Pinto, Capitão de Fragata José Secundino de Gomensoso, Capitão Tenente Francisco Eduviges Bricio, Primeiro Tenente Antonio Marcelino da Ponte Ribeiro, Primeiro Tenente Manuel carneiro da Rocha, e Primeiro Cirurgião Doutor Propercio Pedroso de Albuquerque. $\mathrm{Eu}$, antonio Ferreira Serrano, Segundo difinidor no impedimento do Secretario da Ordem, o escrevi. D. Thereza - Josefina da Fonseca Costa, dama de S.M. a Imperatriz - Luiz Pedreira do Couto Ferraz, Veador da mesma Senhora. - Antonio Manuel de Mello -, Guarda Roupa de S.M.M. o Imperador - Dionisio da Cunha Ribeiro Feijó, Secretario Geral interino do Ministerio do Imperio - O Conego Antonio José de Mello, Capellão de S.S.M.M.I.I. - O Vice-Almirante Joaquim Marques Lisboa - O chefe da Divisão Francisco Manoel Barroso da Silva - Francisco Eduviges Bricio, Capitão Tenente - Antonio Marcelino da Ponte Ribeiro, 1.o Tenente Secretario do Almirante - 0 1.o Tenente Manuel Carneiro da Rocha, ajudante de Ordens. - Primeiro Cirurgião d'Armada Dr. Propicio Pedrosa Barreto de Albuquerque - O Prior da Ordem Bento José Ferreira Ponteiro - Fr. Herculano do Coração de Jesus brito, Prior Commissario - 0 2.0 difinidor Antonio Ferreira Serrano - Procurador, Francisco José Figueiredo - Procurador Marinho da Silva Medeiros - Christiano dos Fojos Correia Cezar, Mestre dos Noviços - Padre Antonio de Mello Muniz Maia - Francisco das Chagas Galvão, Ex-secretario - Amaro José Velloso - Antonio José de Araujo" (PINTO, 1977 : 280-281). 
Tal homenagem prestada à Imperatriz demonstra, mais uma vez, como estavam amalgamados o Estado e a Igreja durante o Império no Brasil.

\section{As cadernetas de viagem de Pedro II : a escrita de si}

33 A historiografia não se cansa de reforçar a paixão de d. Pedro II pelas viagens, tanto aquelas que realizou nas províncias de seu "império nos trópicos", quanto as que fez ao exterior. No caso do Brasil só deixou de visitar as províncias que correspondem ao que hoje conhecemos como regiões Norte e Centro-Oeste, conforme escreveu José Murilo de Carvalho em sua biografia sobre o monarca, onde dedicou um capítulo sobre o tema das viagens - "Pelas Estradas do Brasil e da Europa". Em relação à passagem de Pedro II pela Parahyba do Norte, fez apenas breves menções :

Em 1859, durante o recesso parlamentar, foi a vez de visitar o Norte. (...) Foram quatro meses do Espírito Santo à Paraíba. (...) Depois de percorrer várias cidades do Recôncavo, sempre recebido com entusiasmo, retornou a Salvador para a distribuição da mais importante moeda simbólica das monarquias, avidamente disputada pele elite baiana : títulos nobiliárquicos, comendas, ordens honoríficas. 0 mesmo ritual repetiu-se nas províncias de Alagoas, Sergipe, Paraíba e Pernambuco" (CARVALHO, $2007:$ 139-140).

Fig. 02 - Caderneta de Viagem de D. Pedro II.

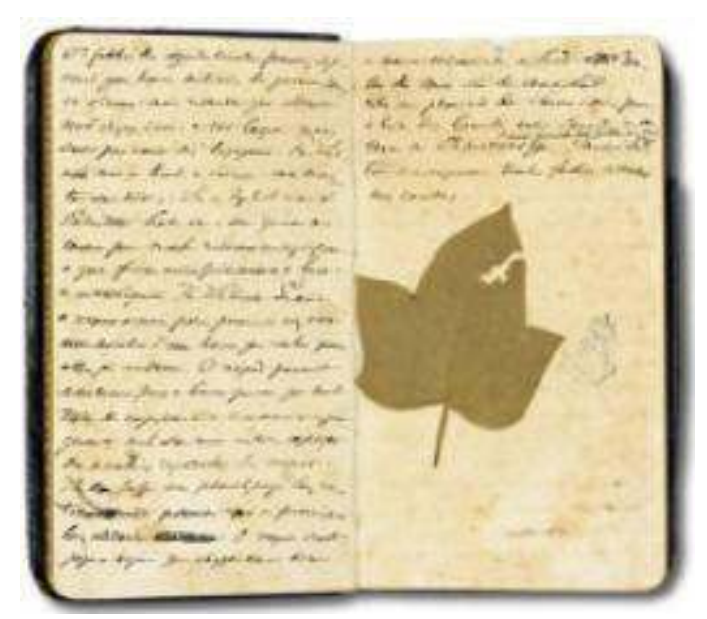

Acervo do Museu Imperial, Petrópolis 


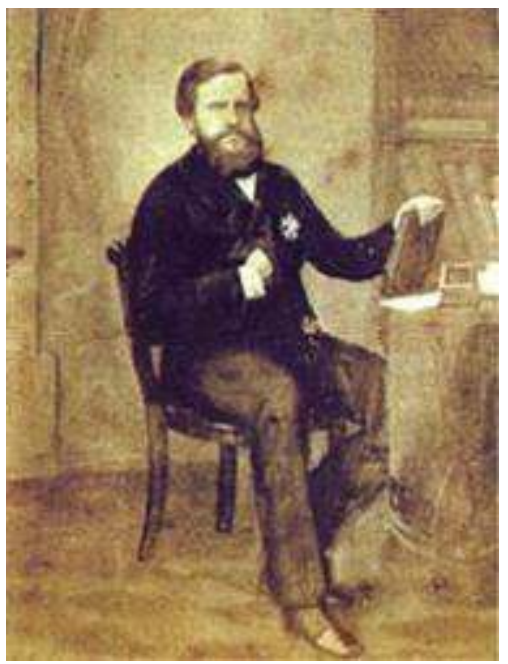

Acervo do Museu Imperial, Petrópolis

Em As Barbas do Imperador, Lilia Moritz Schwarcz também dedicou um capítulo do livro às viagens do monarca - "Um Monarca Itinerante" - além de poucas linhas sobre sua passagem pelas províncias do Norte :

Mas a cidade-corte não era o Brasil, e era preciso que o imperador fosse visto por todo o canto, prestigiando assim as localidades mais distantes. A presença de D. Pedro II em outras cidades e províncias era mesmo necessária até para que a monarquia se fortalecesse e preservasse a unidade nacional. Foi assim que entre 1859 e 1860 o monarca visitou o nordeste, tendo sido recebido com grandes festas na Paraíba, no Espírito Santo 6 , na Bahia, em Pernambuco e em Sergipe (SCHWARCZ, 1998 : 357).

É preciso dizer que bem pouco se escreveu, até o momento, sobre a visita de D. Pedro II às províncias do norte e menos ainda sobre a sua estadia na Parahyba. E é por esses caminhos incertos que estamos nos aventurando neste momento, tateando um terreno ainda marcado, ao menos na produção historiográfica local, por descrições com tom laudatório e pouco crítico, como se pode constatar tanto na brochura de Maurílio de Almeida (1982), já citada, como nos jornais que circularam na capital paraibana à época dos preparativos e da própria recepção do imperador e de seu séquito.Torna-se necessário, portanto, fazer algumas considerações sobre o hábito peculiar do monarca brasileiro, sabidamente conhecido por sua erudição e curiosidade científica, de registrar suas viagens em cadernetas ou diários, prática que era comum aos viajantes europeus do oitocentos que perambularam pelas terras brasileiras. No caso dessas cadernetas de viagem de D. Pedro II, se pode afirmar que este registro ganha maior importância e significado simbólico, na medida em que se torna uma das raras oportunidades de se acompanhar os apontamentos de cunho mais informal feitos por um indivíduo que, ao contrário de outros viajantes comuns ou em expedições científicas e principalmente pela posição social que ocupava, viveu cercado e submetido a regras de conduta e comportamento de uma rigidez acachapante e quase sempre num cotidiano por demais tedioso (SCHWARCZ, 2001b). As viagens do monarca, portanto, podem ser consideradas também para ele como momentos de suspensão duma rotina repetitiva, cheios de oportunidades de novas descobertas e regalos aparentemente simples, mas significativos para seu lazer pessoal. 
Ao contrário daquilo que poderia se esperar, transparece certa liberdade na forma da escrita e nos registros rápidos feitos por D. Pedro II que, pelo que se pode perceber na leitura das páginas escritas com sua letra miúda, gostava de anotar suas ideias na calma da noite, a partir de impressões e registros ligeiros que ia fazendo ao longo do dia sobre lugares, pessoas e situações inusitadas no transcorrer de suas viagens :

O Diário pessoal de suas viagens tinha certa semelhança com aqueles famosos cadernos do jovem D. Pedro V, seu sobrinho, que imperou em Portugal em curto reinado. (...) as notas tomadas pelo imperador durante sua viagem à Paraíba foram manuscritas em cima da perna, alinhavadamente. Não poucas ele redigiu montado a cavalo ou caminhando a pé, em qualquer pausa de propósito atraída. Os apontamentos não primavam pela caligrafia ; as letras se juntavam na formação das palavras nem sempre legíveis. Muitos foram recopiados pelo próprio autor, ganhando clareza. Mas o pente fino deixou de passar pelas madeixas daqueles que foram escritos na Paraíba, que se apresentam em rabiscos e frases soltas. Denunciam pressa (ALMEIDA, 1982: 88-89).

Mas é justamente no tom apressado destes registros que se sobressai um aspecto sempre presente nos interesses do monarca : o funcionamento das instituições e locais de instrução nas paragens que visitava em seus domínios, fossem elas localizadas nas capitais provinciais ou mesmo nas vilas e povoados próximos a elas. Suas observações, muitas vezes curtas mas contundentes e até mesmo ácidas, podem nos auxiliar a perceber um pouco melhor as condições cotidianas da instrução primária e secundária na Parahyba de meados do oitocentos.

\section{A visita de Sua Majestade Imperial às aulas avulsas na capital e no interior da Província e ao Lyceu Provincial}

Em sua passagem pela Parahyba D. Pedro II visitou, nas vilas de Pilar e Mamanguape, as escolas de primeiras letras e anotou sobre elas elementos que permitem espreitar questões relativas ao universo instrucional do período e, desse modo, constatar certos detalhes que as pesquisas recentes na área de História da Educação na Paraíba já vem apontando, ou seja, a precariedade da instrução na província ${ }^{7}$. Ainda assim, o monarca encontrou meninos em uma aula de primeiras letras na vila do Pilar a estudar latim com o padre mestre, que também acumulava a função de presidente da câmara, segundo nos informa, orgulhoso, Maurílio de Almeida (1982: 105).

Como parte das atividades que o monarca julgava importantes durante o périplo pelas províncias de seu império sempre se destacava a de examinar escolas de meninos, de meninas e seus mestres, usualmente de forma inesperada e sem muita preparação prévia. A sensação que fica da leitura de seus escritos é a de alguém que quer apurar de forma mais exata a real situação do letramento das crianças no Brasil do oitocentos. A Parahyba não foi exceção e mesmo com pouco tempo disponível, D. Pedro II reservou espaço para essas suas visitas inesperadas que, muitas vezes deixavam as crianças apreensivas. 
Fig. 04 - Palácio do Governo (em $1^{\circ}$ plano), Igreja do Colégio (ao centro) e Lyceu Provincial (ao fundo)

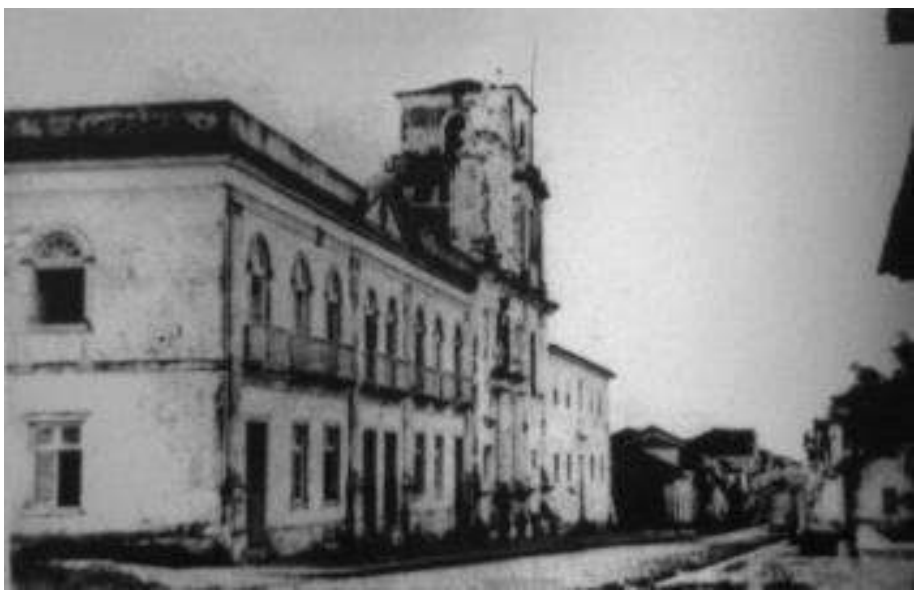

Foto anônima, 1878 ; acervo Humberto Nóbrega, Centro Universitário de João Pessoa

Em seu diário o monarca registrou a visita ao local destinado à instrução secundária na província, o Lyceu Provincial - localizado então no antigo prédio que abrigou o Seminário dos Jesuítas, ao lado do Palácio do Governo em que se hospedou com a comitiva imperial em seu séjour paraibano -, instituição que chegou a ser chamada de "Glorioso Templo de Sabedoria"s (FERRONATO, $2012: 140$ ). O monarca também visitou, na véspera de seu regresso à Corte, aulas de primeiras letras destinadas às meninas e aos meninos, arguindo muitos dos estudantes pessoalmente. Pedia que lessem trechos da Bíblia ; que fizessem contas de somar e dividir ; preocupa-se com as condições das casas onde as aulas eram ministradas; anotava suas impressões sobre a conduta dos professores e por vezes escrevia, em suas anotações, de forma quase telegráfica, " $O$ Professor parece bom", ou ainda, "Mau professor" (ALMEIDA, 1982 : 110-111).

41 Sempre atento ao número de matrículas de cada um dos professores e à lista de frequência, D. Pedro constantemente fazia comentários, em sua caderneta de viagem, sobre a caligrafia dos alunos, ou seja, procurava inspecionar as aulas de perto, como alguém que conhece e se interessa pela instrução pública e particular. Ou, como diria um verso do hino de Tertuliano de Medeiros, tratava-se de "um monarca estudioso" (ALMEIDA, $1982: 87$ ).

Em relação ao Lyceu Provincial, a caderneta do Imperador destaca, principalmente, o total de alunos matriculados na maior instituição de instrução pública na província: "Liceu. 100 meninos" (ALMEIDA, 1982 : 110).

\section{Ao tipo de um gran finale...}

Como era de praxe nas visitas imperiais às províncias, antes mesmo de deixar o local visitado, como aconteceu na Bahia e em Pernambuco, ou depois do retorno à Corte, como ocorreu em relação à Paraíba, o gabinete do monarca providenciava a concessão de títulos e comendas em reconhecimento àqueles cidadãos que, de alguma forma, houvessem contribuído e facilitado a estadia e realização dos compromissos públicos de Suas Majestades Imperiais em seus séjours.Tal prática não foi destoante na Parahyba do Norte, portanto. Mas ela pode nos dar uma noção dos indivíduos da elite local que conseguiram reforçar seus poderes simbólicos, políticos e sua influência na rede de 
relações que compunha a tessitura social da pequena província. Maurílio de Almeida destaca a concessão de dois títulos de Barão: um ao Dr. Flávio Clementino da Silva Freire, Barão de Mamanguape ; e outro ao Coronel José Teixeira de Vasconcelos, Barão de Maraú. Também foram distribuídas, da Ordem da Rosa, seis comendas, enquanto 22 indivíduos receberam o título de oficial e outros 36, o de cavaleiro. Da Ordem de Cristo se distribuiu 4 comendas e 25 indivíduos receberam o título de cavaleiro (ALMEIDA, 1982: 115-117).Entre estes homens estavam militares, padres, médicos, advogados, funcionários públicos de alta patente e até mesmo proprietários rurais. Seria possível, a partir da lista destes agraciados, proceder uma breve prosopografia, que no entanto não caberia no espaço deste texto, mas certamente tal cruzamento de dados sinalizaria importantes relações de poder local que foram consolidadas a partir da visita imperial à Parahyba do Norte.

Como Gran Finale da estadia de Suas Majestades Imperiais na província, portanto, ficou como herança, em nosso entendimento, o estreitamento dos laços de poder simbólico entre estes membros da elite local e o poder central do Império, pois as honras concedidas pelo Imperador após as festas e celebrações organizadas em sua homenagem pressupunham, implicitamente, o acordo tácito para a manutenção do status quo no intrincado jogo de influências na política do Segundo Reinado.

\section{BIBLIOGRAFIA}

ALMEIDA, Maurílio Augusto de. Presença de D. Pedro II na Paraiba. 2. ed. Petrópolis, Vozes, 1982 [1975].

ARAÚJO, Rose Mary de Souza. Escola Normal na Parahyba do Norte : movimento e constituição da formação de professores no século XIX. Tese (Doutorado em Educação). Universidade Federal da Paraíba. João Pessoa, 2010.

CALMON, Pedro. História de D. Pedro II. Tomo segundo : cultura e política, paz e guerra (1853-1870). Rio de Janeiro, Paz e Terra, 1975.

CARVALHO, Jandynéa de Paula. "Ser Professor" : o processo de controle do magistério na Província da Parahyba do Norte na segunda metade do século XIX. Monografia (Graduação em História). Universidade Federal da Paraíba. João Pessoa, 2006.

CARVALHO, José Murilo de. D. Pedro II : ser ou não ser. São Paulo, Companhia das Letras, 2007.

CUNHA, Ambrosio Fernão da. Relatorio apresentado ao Excellentissimo Sr. Dr. Luiz Antonio da Silva Nunes, presidente da Provincia da Parahyba do Norte pelo Excellentissimo Sr. Dr. Ambrosio Leitão da Cunha no acto de passar a administração da provincia em 13 de abril de 1860. Parahyba, Typographia Parahybana, 1860. Disponível em : . Acesso em : 21 mar. 2012.

FERRONATO. Cristiano de Jesus. Das aulas avulsas ao Lyceu Provincial : as primeiras configurações do ensino secundário na Província da Parahyba do Norte. Tese (Doutorado em Educação). Universidade Federal da Paraíba. João Pessoa, 2012. 
KIDDER, Daniel Parish. Sketches of residence and travels in Brazil, embracing historical and geographical notices of the Empire and its several provinces. vol. II. Philadelphia, Sorin \& Ball, 1845. Disponível em : . Acesso em : 16 ago. 2012.

LIMA, Guaraciane Mendonça de. 0 Colégio de Educandos e Artífices da Parahyba do Norte (1865-1874). Monografia (Graduação em História). Universidade Federal da Paraíba. João Pessoa, 2005.

LIMA, Guaraciane Mendonça de. O Collégio de Educandos Artífices (1865-1874) : a infância desvalida da Parahyba do Norte. Dissertação (Mestrado em História). Universidade Federal da Paraíba. João Pessoa, 2008

MIRANDA, Itacyara Viana. Saber e Medo : métodos disciplinares e punitivos na Província da Parahyba do Norte (1822-1864). Monografia (Graduação em História). Universidade Federal da Paraíba. João Pessoa, 2009.

MIRANDA, Itacyara Viana. Instrução, disciplina e civilização : uma perspectiva de leitura acerca das aulas públicas e particulares na Parahyba do Norte (1860-1889). Dissertação (Mestrado em História). Universidade Federal da Paraíba. João Pessoa, 2012.P. de S. Memórias da viagem de SS. Magestades Imperiais às províncias da Bahia, Pernambuco, Parahiba, Alagoas, Sergipe, e Espirito Santo. 2 tomos. Rio de Janeiro, Typographia e Livraria de B. X. Pinto de Sousa, 1861/1862. Disponível em : . Acesso em : 21 mar. 2012.

PINTO, Irineu Ferreira. Datas e notas para a História da Paraíba - vol. 2. 2. ed. facsimilar. João Pessoa, Ed. Universitária/ UFPB, 1977 [1908].

RAMALHO, José. Viagem do imperador Pedro II as províncias do Norte : excursão a cidade paraibana de Mamanguape. Revista do Instituto Histórico e Geográfico Paraibano, João Pessoa, IHGP, n. 14, 1961, p. 130.

ROHAN, Henrique de Beaurepaire. Relatorio apresentado á Assembléa Legislativa da provincia da Parahyba do Norte em 20 de setembro de 1858 pelo presidente, Henrique de Beaurepaire Rohan. Parahyba, Typ. de José Rodrigues da Costa, 1858. Disponível em : . Acesso em : 17 ago. 2012.

ROHAN, Henrique de Beaurepaire. Relatorio apresentado ao Illm. e Exm. Sr. Dr. Ambrósio Leitão da Cunha, no acto de tomar posse do cargo de presidente da provincia da Parahyba do Norte. Parahyba, Typ. de José Rodrigues da Costa, 1859. Disponível em : . Acesso em : 14 ago. 2012.

SCHWARCZ, Lilia Moritz. As barbas do imperador : D. Pedro II, um monarca nos trópicos. São Paulo, Companhia das Letras, 1998.

SCHWARCZ, Lilia Moritz. Viajantes em meio ao Império das festas. In : JANCSÓ, István \& KANTOR, Iris (orgs.). Festa : cultura e sociabilidade na América portuguesa - vol. II. São Paulo, Edusp/ Hucitec/ Imprensa Oficial, 2001a, p. 603-619.

SCHWARCZ, Lilia Moritz. O Império em procissão : ritos e símbolos do Segundo Reinado. Rio de Janeiro, Jorge Zahar, 2001b.

SOUZA, Thiago Oliveira de. A Instrução Paraibana contada através dos impressos jornalísticos do século XIX (1858-1889). Monografia (Graduação em História). Universidade Federal da Paraíba. João Pessoa, 2010.

TEIXEIRA, Mariana Marques. Um olhar sobre a configuração da profissão docente na Parahyba Oitocentista (1822-1864). Monografia (Graduação em História). Universidade Federal da Paraíba. João Pessoa, 2009. 


\section{NOTAS}

1. D. Pedro II registrou em seu diário de viagem que em algumas localidades do interior da província os preparativos para a sua chegada não aconteceram ou deixaram a desejar.

2. A brochura em questão foi escrita e publicada pela primeira vez em 1975, por um médico paraibano (8 jun. 1926/14 jun. 1988) que se autodenominava historiador, afirmando que esta era uma atividade exercida por vocação. Na folha de rosto de sua publicação financiada com recursos próprios encontram-se as seguintes indicações sobre ele : era membro da Sociedade Brasileira de Médicos Escritores, da Academia Paraibana de Letras, da Academia Brasileira de História, do Instituto Histórico e Geográfico Paraibano, do Instituto de Genealogia e Heráldica da Paraíba, da Academia de Artes e Letras do Nordeste. Os historiadores de ofício costumam denominar esse tipo de escrita historiográfica de memorialista.

3. Treliças de madeira, utilizadas nas janelas e balcões para isolar o interior da casa das vistas dos passantes.

4. Notação de 1 conto de réis, equivalente à quantia de 1 milhão de réis.

5. O Te Deum é um hino litúrgico atribuído, na tradição católica, a Santo Ambrósio e Santo Agostinho, iniciado com a expressão "Te Deum Laudamus" (“A Vós, Deus, louvamos”). Segundo a tradição, este hino foi improvisado na Catedral de Milão num arroubo de fervor religioso desses santos. Na tradição portuguesa, o hino, recorrentemente musicado por diferentes compositores sacros, deveria ser entoado numa cerimônia religiosa sempre que o monarca visitasse alguma de suas possessões, e esta prática foi transferida ao Império brasileiro.

6. Note-se que o Espírito Santo não era considerado como uma das províncias do Norte no XIX, mas sim "do Leste", e foi visitada no retorno à Corte, já que se encontrava praticamente a meio caminho entre Sergipe e o Rio de Janeiro e, provavelmente, foi inserido no roteiro da frota imperial mais como ponto de reabastecimento e descanso do que, necessariamente, por sua importância política ou econômica à época.

7. Veja-se, por exemplo, as monografias de graduação em História, bem como as dissertações de mestrado e teses de doutorado produzidas no âmbito do GHENO/UFPB, junto aos Programas de Pós-Graduação em História e em Educação da Universidade Federal da Paraíba : ARAÚJO, 2010 ; CARVALHO, 2006 ; FERRONATO, 2012 ; LIMA, 2005 e 2008 ; MIRANDA, 2009 e 2012 ; SOUZA, 2010 ; TEIXEIRA, 2009.

8. Expressão cunhada pelo diretor da instrução pública, Manrique Victor de Lima, em seu discurso de abertura das aulas do Lyceu Provincial, em 2 de março de1846.

\section{RESUMOS}

Uma marcante característica da biografia de D. Pedro II foi seu gosto pelas viagens, tanto dentro de seus domínios como também por terras estrangeiras. Quando viajava pelas províncias brasileiras, no entanto, produzia-se, quanto mais periféricas eram, uma situação de exceção para seus súditos. Essa suspensão da vida corriqueira - motivada pela visita imperial - dava ocasião a celebrações que enalteciam Sua Majestade e reforçavam, didaticamente, os lugares de poder e seu simbolismo nas relações sociais locais. Não foi diferente quando o imperador esteve na Parahyba do Norte, entre 24 e 30 de dezembro de 1859, vindo de dois meses partilhados entre a Bahia e Pernambuco e antes de voltar à Corte, passando por Alagoas, Sergipe e Espírito Santo. Pretendemos analisar as celebrações promovidas durante a visita de Pedro II e sua comitiva à 
Parahyba, tentando compreender os poderes simbólicos e as estratégias de reafirmação engendradas pela elite local frente à plebe miúda.

Une caractéristique frappante de la biographie de D. Pedro II, Empereur du Brésil (1840-1889), était son goût pour les voyages, dans ses propres domaines comme dans divers pays étrangers. Ses visites aux provinces brésiliennes constituaient une situation d'exception pour ses sujets. La visite impériale produisait une suspension de la vie ordinaire et était toujours l'occasion de solennelles célébrations de Sa Majesté, en renforçant, didactiquement, les lieux de pouvoir et leur symbolisme dans les relations sociales locales. Ce fut également le cas quand l'empereur se déplaça à Parahyba du Nord, du 24 au 30 Décembre1859, après deux mois partagés entre Bahia et Pernambuco, avant de retourner à la Cour en passant par les provinces de Alagoas, Sergipe et Espírito Santo. Nous nous proposons d'analyser les célébrations réalisées au cours de la visite de D. Pedro II et de son entourage à Parahyba, en essayant de comprendre leur pouvoir symbolique et leur rôle dans les stratégies engendrées par les élites locales pour renforcer leur position face aux classes subalternes.

\section{ÍNDICE}

Mots-clés: D. Pedro II, visite impériale, Parahyba du Nord, pouvoir symbolique, célébrations Palavras-chave: D. Pedro II, visita imperial, Parahyba do Norte, poderes simbólicos, comemorações

\section{AUTORES}

\section{CARLA MARY S. OLIVEIRA}

PPGH-UFPB História da Arte/ História Cultural

cms-oliveira[at]uol.com.br

\section{CLÁUDIA ENGLER CURY}

PPGH-UFPB História da Educação/História do Brasil Imperial

claudiacury[at]terra.com.br 